\section{Case Reports in Neurology}

Case Rep Neurol 2020;12:373-377

DOI: $10.1159 / 000512322$
Published online: November 2, 2020

(C) 2020 The Author(s)

Published by S. Karger AG, Basel www.karger.com/crn

This article is licensed under the Creative Commons Attribution-NonCommercial 4.0 International License (CC BY-NC) (http://www.karger.com/Services/OpenAccessLicense). Usage and distribution for commercial purposes requires written permission.

\title{
Multiple Microbleeds: A Serious Neurological Manifestation in a Critically III COVID-19 Patient
}

\author{
Khawaja Hassan Haroon ${ }^{a, b}$ Satya Narayana Patro ${ }^{a, b} \quad$ Suhail Hussain ${ }^{a}$ \\ AbdulAziz Zafar a, b Ahmad Muhammad ${ }^{a, b}$ \\ aNeuroscience Institute, Hamad Medical Corporation, Doha, Qatar; ${ }^{b}$ Weill Cornell \\ Medicine-Qatar, Doha, Qatar
}

\section{Keywords}

COVID-19 · Cerebral microbleeds · Critically ill patients

\begin{abstract}
Coronavirus disease 2019 (COVID-19) is a viral illness caused by the novel severe acute respiratory syndrome coronavirus 2 (SARS-CoV-2). There is worldwide emerging evidence of multisystem involvement including different neurological manifestations in COVID-19 patients. As a result, healthcare systems worldwide are not only experiencing diagnostic but also therapeutic and prognostic challenges with COVID-19-related complications. Cerebral microbleeds and leukoencephalopathy have been described in COVID-19 patients; although the mechanism remains unknown, possibilities include endotheliitis with thrombotic microangiopathy, excessive inflammation, prolonged respiratory failure, and hypoxemia. We describe here the clinical, radiological, and laboratory findings as well as the 90-day outcome of a 72-year-old gentleman who presented with severe SARS-CoV-2 infection, leading to diffuse cerebral microhemorrhages and ischemic infarct causing severe morbidity. He was tested positive for COVID-19 confirmed by reverse transcriptase polymerase chain reaction.
\end{abstract}




\section{Case Reports in Neurology}

Case Rep Neurol 2020;12:373-377

DOI: $10.1159 / 000512322$

Haroon et al.: Multiple Cerebral Microbleeds in a COVID-19 Patient

\section{Case Presentation}

A 72-year-old gentleman, with no known past medical history and no history of trauma, was admitted with fever, dyspnea, dry mucous membranes, and tongue ulceration. He was tachypneic with respiratory rate $29 / \mathrm{min}$, hypoxic with $\mathrm{O}_{2}$ saturation $80 \%$ on room air, improved to $92 \%$ on $10 \mathrm{~L} / \mathrm{min}_{2}$, temperature $37.6^{\circ} \mathrm{C}$, tachycardic with heart rate $120 \mathrm{bpm}$ and blood pressure $120 / 83 \mathrm{~mm} \mathrm{Hg}$. He was admitted to the ICU, initially managed with continuous positive airway pressure and then started on $15 \mathrm{~L} / \mathrm{min} \mathrm{O}_{2}$. His admission blood tests showed high inflammatory markers including white cell $18 \times 10^{3} / \mu \mathrm{L}$ (reference $4-10 \times 10^{3} / \mu \mathrm{L}$ ), neutrophils $14 \times 10^{3} / \mathrm{fL}$ (reference 2-7 × 103/fL), CRP $225 \mathrm{mg} / \mathrm{L}$ (reference 0-5 mg/L), ferritin $6,166 \mu \mathrm{g} / \mathrm{L}$ (reference 30-553 $\mu \mathrm{g} / \mathrm{L}$ ), D-dimer $1.5 \mathrm{mg} / \mathrm{L}$ (reference 0-0.49 mg/L), IL-6 $65 \mathrm{pg} / \mathrm{mL}$ (reference $<7 \mathrm{pg} / \mathrm{mL}$ ), LDH $588 \mathrm{U} / \mathrm{L}$ (reference 135-225 U/L), and lymphocytes $0.5 \times 10^{3} / \mu \mathrm{L}$ (reference $1-3 \times 10^{3} / \mu \mathrm{L}$ ); chest X-ray revealed bilateral lower zone infiltrates. Coronavirus disease 2019 (COVID-19) reverse transcriptase polymerase chain reaction was positive. ECG showed sinus tachycardia with a rate of $140 \mathrm{bpm}$.

The patient was treated as per local COVID-19 treatment protocol and was also given prophylactic low-molecular-weight heparin (LMWH). He deteriorated over the next 2 days and became agitated, more dyspneic, and delirious. Chest X-ray showed worsening bilateral infiltrates with left lower zone collapse and consolidation. He developed acute respiratory distress syndrome secondary to COVID-19 which led to intubation while being in the ICU. As part of investigations for acute delirium to rule out a cerebral cause, a noncontrast CT of the head (Fig. 1a) was performed which did not demonstrate any acute pathology. His renal functions on admission showed urea $17 \mathrm{mmol} / \mathrm{L}$ (reference $2.8-8.1 \mathrm{mmol} / \mathrm{L}$ ) with creatinine $152 \mu \mathrm{mol} / \mathrm{L}$ (reference 62-106) which gradually deteriorated to urea $38 \mathrm{mmol} / \mathrm{L}$ and creatinine $223 \mu \mathrm{mol} / \mathrm{L}$. He developed sepsis with multiorgan failure. He needed renal dialysis on a PRN basis for acute kidney injury. He remained intubated for 3 weeks and as it was difficult to wean him off ventilator support; he needed tracheostomy.

After tracheostomy, his conscious level remained low and he was noticed to have loss of movement in the left arm. On examination, he was drowsy with slow grimace to painful stimuli. His Glasgow Coma Scale score was E1VTM4. His pupils were slowly reactive. The left upper limb showed power $0 / 5$, some movement in the right arm, but not to painful stimulus, and absent movement in both lower limbs with equivocal bilateral planters.

Noncontrast MRI and MRA of the head were performed (Fig. 1b-e) which revealed two acute to early subacute lacunar infarcts in the right frontal deep white matter and a few small FLAIR hyperintense foci in the bilateral periventricular white matter with no significant stenosis or occlusion of the intracranial arteries. Susceptibility-weighted imaging (SWI) (Fig. 1fh) further demonstrated multiple microhemorrhages diffusely distributed in the bilateral cortical-juxtacortical regions, deep white matter, basal ganglia, the corpus callosum, the brain stem, and the cerebellum, a pattern seen in COVID-19-related cerebral manifestations.

Cerebrospinal fluid workup was negative for infectious or inflammatory meningitis or encephalitis and negative for coronavirus polymerase chain reaction assay. We continued prophylactic LMWH in view of critical COVID-19 infection as venous thromboembolism prophylaxis while carefully monitoring his neurological status. His condition did not change afterwards. It has been 3 months since the onset of his symptoms. He needs specialized nursing care as a tracheostomized patient with a low Glasgow Coma Scale score and a modified Rankin scale score of 5. 


\section{Case Reports in Neurology}

Case Rep Neurol 2020;12:373-377

DOI: 10.1159/000512322

(c) 2020 The Author(s). Published by S. Karger AG, Basel www.karger.com/crn

Haroon et al:: Multiple Cerebral Microbleeds in a COVID-19 Patient

\section{Discussion}

COVID-19 is caused by the novel severe acute respiratory syndrome coronavirus 2 (SARSCOV-2) which primarily targets the respiratory system. However, we are seeing emerging evidence of different prominent neurological complications in patients with COVID-19. COVID19-associated cerebral microbleeds and diffuse leukoencephalopathy have been described; the pathophysiological mechanisms of these manifestations remain unknown, but possibilities include endotheliitis with thrombotic microangiopathy and prolonged respiratory failure and hypoxemia [1-3].

Critical illness-associated cerebral microbleeds are only detected by blood-sensitive MRI sequences. This is a rare condition reported in patients with acute respiratory failure, requiring mechanical ventilation and sometimes undergoing extracorporeal membrane oxygenation [4]. There have been case reports and series describing juxtacortical and callosal microbleeds in critically ill COVID-19 patients [2, 3, 5].

Patients who developed delayed posthypoxic leukoencephalopathy have shown similar white matter microhemorrhages with predominant distribution in the juxtacortical white matter and corpus callosum, which are thought to be related to severe hypoxia [6]. Similar cerebral microbleeds have been described in high altitude exposure, possibly relating to hypoxemia and disruption of the blood-brain barrier [7]. Alternatively, small vessel vasculitis can also potentially lead to multiple microhemorrhages. Callosal microhemorrhages resemble those seen with posttraumatic diffuse axonal injury [2], but clearly in our patient, there was no history of trauma.

Patients with COVID-19-related cerebral microbleeds and/or leukoencephalopathy have critical illness with high mortality, longer hospital stay, and poor functional outcome $[3,8]$. Our patient with findings of cerebral microbleeds with COVID-19 had critical illness with high burden of inflammation, as he needed prolonged ventilatory support and hospitalization. His acute infarct was managed conservatively and antiplatelets were not initiated in view of the large number of microbleeds with fear of their conversion to macrobleeds. He was treated as per local COVID-19 treatment protocol including LMWH as venous thromboembolism prophylaxis while carefully monitoring his neurological status.

In a series of 16 patients who had COVID-19-related neurological manifestations and underwent MRI of the head, 11 patients showed punctate hemorrhages on MRI-SWI sequences. One patient died and had a postmortem, which showed numerous punctate hemorrhages in the cortical gray-white matter junction and in the deep white matter corresponding to MRISWI, but also showed microscopic ischemic lesions which were not present on MRI, likely due to their small size relative to the spatial resolution of clinical diffusion-weighted imaging [9].

Currently, worldwide COVID-19 mortality is $5 \%$ with $1 \%$ critically ill inpatients, but we do not have significant data regarding the morbidity caused by virus. We think that the rate of morbidity due to SARS-COV-2-related complications, including neurological manifestations, is higher, with significant financial and social implications in the near future. We need to recognize these neurological manifestations early during disease. As evidence is still accumulating, we need to establish the pathophysiological mechanisms as well as appropriate treatment for these neurological complications in COVID-19 patients. 


\section{Case Reports in Neurology}

\begin{tabular}{l|l}
\hline Case Rep Neurol 2020;12:373-377 \\
\hline DOI: 10.1159/000512322 & $\begin{array}{l}\text { @ 2020 The Author(s). Published by S. Karger AG, Basel } \\
\text { www.karger.com/crn }\end{array}$ \\
\hline
\end{tabular}

Haroon et al.: Multiple Cerebral Microbleeds in a COVID-19 Patient

\section{Conclusion}

Our patient with critical illness due to SARS-COV-2, unfortunately, has achieved poor functional outcome. We have limited knowledge of COVID-19-related neurological manifestations and their appropriate management. We need further research and clinical trials to address these issues to achieve the best possible outcome for our patients.

\section{Statement of Ethics}

This article was conducted ethically in accordance with the World Medical Association Declaration of Helsinki. The subject in this paper gave written informed consent to publish his case, including publication of images.

\section{Conflict of Interest Statement}

The authors have no conflicts of interest to disclose.

\section{Funding Sources}

No funding was received.

\section{Author Contributions}

K.H. Haroon: patient management, manuscript development, literature review, critical review. S.N. Patro: image review and selection. S. Hussain and A. Zafar: critical review. A. Muhammad: manuscript development, literature review, critical review.

\section{References}

1 Varga Z, Flammer AJ, Steiger P, Haberecker M, Andermatt R, Zinkernagel AS, et al. Endothelial cell infection and endotheliitis in COVID-19. Lancet. 2020 May;395(10234):1417-8.

2 Radmanesh A, Derman A, Lui YW, Raz E, Loh JP, Hagiwara M, et al. COVID-19-associated diffuse leukoencephalopathy and microhemorrhages. Radiology. 2020 Oct;297(1):E223-7.

3 Agarwal S, Jain R, Dogra S, Krieger P, Lewis A, Nguyen V, et al. Cerebral microbleeds and leukoencephalopathy in critically ill patients with COVID-19. Stroke. 2020 Sep;51(9):2649-55.

4 Fanou EM, Coutinho JM, Shannon P, Kiehl TR, Levi MM, Wilcox ME, et al. Critical Illness-Associated Cerebral Microbleeds. Stroke. 2017 Apr;48(4):1085-7.

5 Cannac 0, Martinez-Almoyna L, Hraiech S. Critical illness-associated cerebral microbleeds in COVID-19 acute respiratory distress syndrome. Neurology. 2020 Sep;95(11):498-9.

6 Breit H, Jhaveri M, John S. Concomitant delayed posthypoxic leukoencephalopathy and critical illness microbleeds. Neurol Clin Pract. 2018 Oct;8(5):e31-3.

7 Kallenberg K, Dehnert C, Dörfler A, Schellinger PD, Bailey DM, Knauth M, et al. Microhemorrhages in nonfatal high-altitude cerebral edema. J Cereb Blood Flow Metab. 2008 Sep;28(9):1635-42.

8 Lin E, Lantos JE, Strauss SB, Phillips CD, Campion TR Jr, Navi BB, et al. Brain imaging of patients with COVID-19: findings at an academic institution during the height of the outbreak in New York City. AJNR Am J Neuroradiol. 2020 doi: 10.3174/ajnr.A6793 [Epub ahead of print].

9 Conklin J, Frosch MP, Mukerji S, Rapalino O, Maher M, Schaefer PW, et al. Cerebral microvascular injury in severe COVID-19. medRxiv. 2020 doi: 10.1101/2020.07.21.20159376 [Preprint]. 


\section{Case Reports in Neurology}
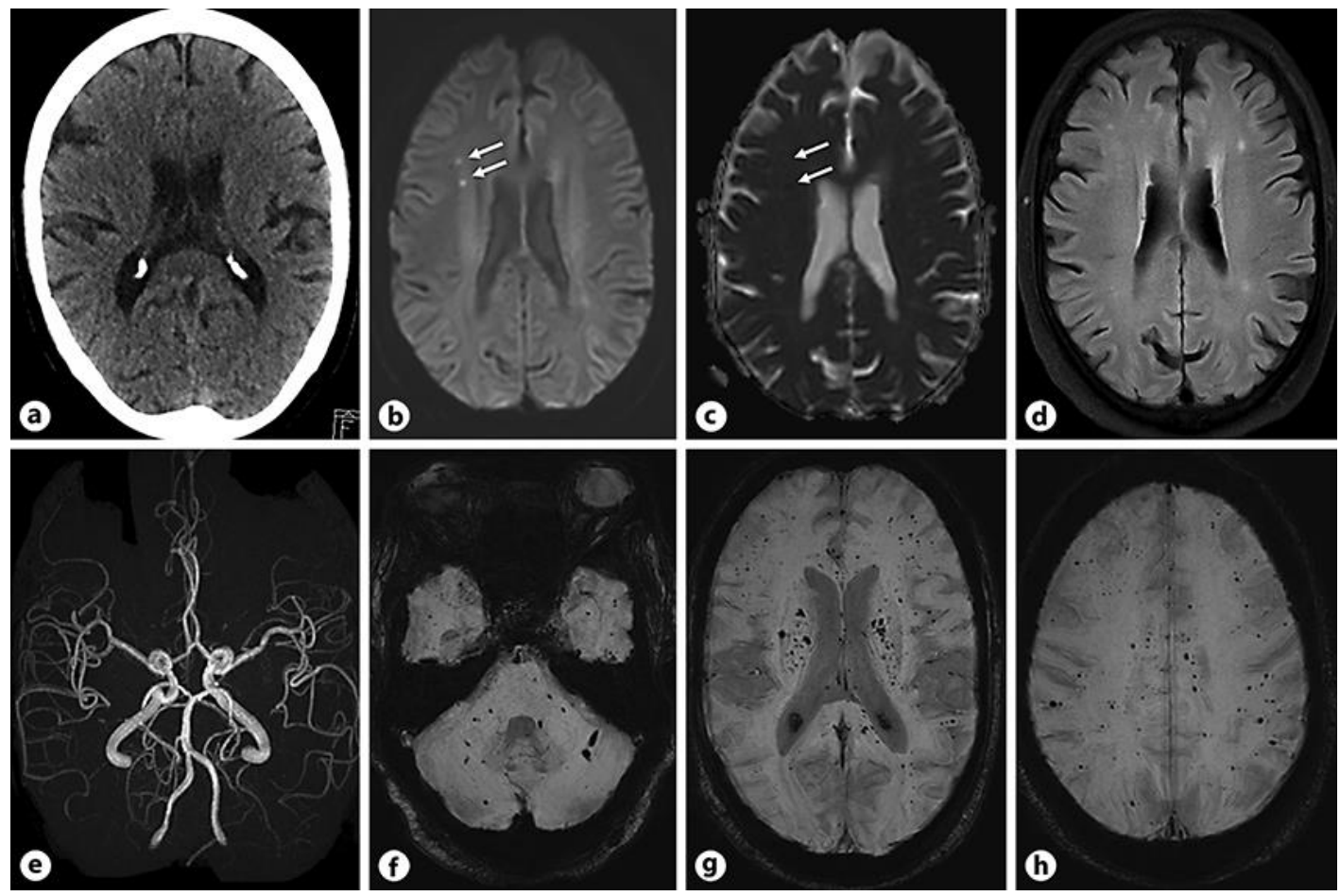

Fig. 1. a Axial CT section of the head at the level of the corpus callosum with no obvious hemorrhage or infarct. b, c Axial diffusion-weighted image and corresponding apparent diffusion coefficient map showing two foci of acute to early subacute lacunar infarcts in the right frontal white matter (white arrows). $\mathbf{d}$ Axial FLAIR image revealing a few small hyperintense foci in the bilateral periventricular and subcortical white matter. e Three-dimensional time of flight maximum intensity projection reconstruction of the intracranial arteries showing no significant stenosis or occlusion of the intracranial arteries. $\mathbf{f}-\mathbf{h}$ Axial susceptibility-weighted images at different levels demonstrating multiple microhemorrhages diffusely distributed throughout the brain parenchyma, including the basal ganglia and the corpus callosum. 